\title{
Pitting corrosion of polycrystalline annealed copper in alkaline sodium perchlorate solutions containing benzotriazole
}

\author{
M. M. LAZ, R. M. SOUTO, S. GONZÁLEZ, R. C. SAlVAREZZA,* A. J. ARVIA* \\ Departamento de Química Fisica, Universidad de La Laguna, Tenerife, Spain
}

Received 2 July 1991; revised 27 November 1991

The pitting corrosion of copper in alkaline solutions in the presence of benzotriazole (BTA) was investigated. The presence of BTA shifts the breakdown $\left(E_{\mathrm{b}}\right)$ and the repassivating $\left(E_{\mathrm{p}}\right)$ potentials positively with respect to the blanks. However, the shift of $E_{\mathrm{p}}$ becomes smaller than that of $E_{\mathrm{b}}$, particularly at $\mathrm{pH} 9$ and 11 . Pitting corrosion involves the formation of crystallographic pits. The kinetics of the process fits a nucleation and growth mechanism involving instantaneous nucleation and 3D growth under charge transfer control. The spatial distribution of pits indicates that there is no marked influence of a pit on the nucleation and growth of other pits.

\section{Introduction}

Protection characteristics of anodic layers in relation to the corrosion and passivation of copper in aqueous solutions of different electrolyte composition were extensively investigated over a wide range of $\mathrm{pH}[1,2]$. The structure of the passivating layers formed on copper in alkaline solutions in the absence of inhibitors was related to a composite duplex layer consisting of an inner $\mathrm{Cu}$ (I) oxide layer and an outer $\mathrm{Cu}(\mathrm{II})$ oxide layer [3-7], their stability and protective characteristics depending considerably on the applied potential range and the composition of the solution. Accordingly, in the presence of agressive anions such as $\mathrm{Cl}^{-}$ and $\mathrm{ClO}_{4}^{-}$-ions a characteristic breakdown potential $\left(E_{\mathrm{b}}\right)$ of the passive layer associated with the initiation of copper pitting can be determined [2, 8, 9]. From the practical standpoint it is of interest to increase the value of $E_{\mathrm{b}}$, for instance, by using inhibitors. In fact it is known that benzotriazole (BTA) is one of the most effective inhibitors for copper corrosion [10] in many aqueous environments [11-20]. BTA efficiency for copper protection increases with $\mathrm{pH}$, and for alkaline solutions the protective characteristics last for a relatively long time [18].

The inhibition mechanism by BTA for copper corrosion involves the formation of a polymeric complex containing cuprous ions, $[\mathrm{Cu}(\mathrm{I}) \mathrm{BTA}]_{n}[14,16,17$, $19,21]$, as concluded from i.r. reflectance spectroscopy [14], X-ray photoelectron spectroscopy [19], scanning electron microscopy $[20,22]$, and surface enhanced raman spectroscopy [23-27] data. It has also been reported that the complex polymer is underlaid with a cuprous oxide layer to form a bilayer structure $[22,28,29]$. It is known that the copper electrodissolution occurs at potentials more positive with increasing BTA concentration, and that the reaction mechanism is the same as that for copper in BTA-free solutions [30]. On the other hand, an alternative mechanism based on the adsorption of BTA on copper has also been advanced [15, 31].

The present work refers to the behaviour of copper in moderate alkaline sodium perchlorate solutions containing BTA at various $\mathrm{pH}$, particularly in relation to the initiation of pitting corrosion of copper. A kinetic model based upon the nucleation and growth mechanism is presented for describing the breakdown of the protective layer formed on copper in the presence of BTA.

\section{Experimental}

A three-electrode electrochemical cell was used. Working electrodes consisted of flat discs $(0.3 \mathrm{~cm} \mathrm{dia.})$ obtained by cutting electrolytic copper rods. First, the electrode surface was mechanically polished by employing a gradual sequence of fine-grained emery papers ranging from 30 to $5 \mu \mathrm{m}$ grit. After cleaning and drying, the copper specimens were annealed at $500^{\circ} \mathrm{C}$ for $2 \mathrm{~h}$ under a few millimetres pressure of argon, following the procedure described in [32], to minimize residual mechanical stresses and to achieve a reproducible grain size distribution. Subsequently, the specimens were electropolished in $85 \%$ ortho-phosphoric acid at $0.3 \mathrm{~A} \mathrm{~cm}^{-2}$ for 5 to $10 \mathrm{~min}$. Finally, the electropolished electrodes were rinsed thoroughly with water and dried in air. Each working electrode was mounted in a vertical rotating shaft and the contact between the disc surface and the solution was made through a hanging meniscus [33]. The potential of the working electrode was measured against a saturated $\mathrm{NaCl}-$ calomel electrode (SSCE). Potentials in the text are referred to the SSCE scale. A cylindrical platinum grid was used as counter electrode. 


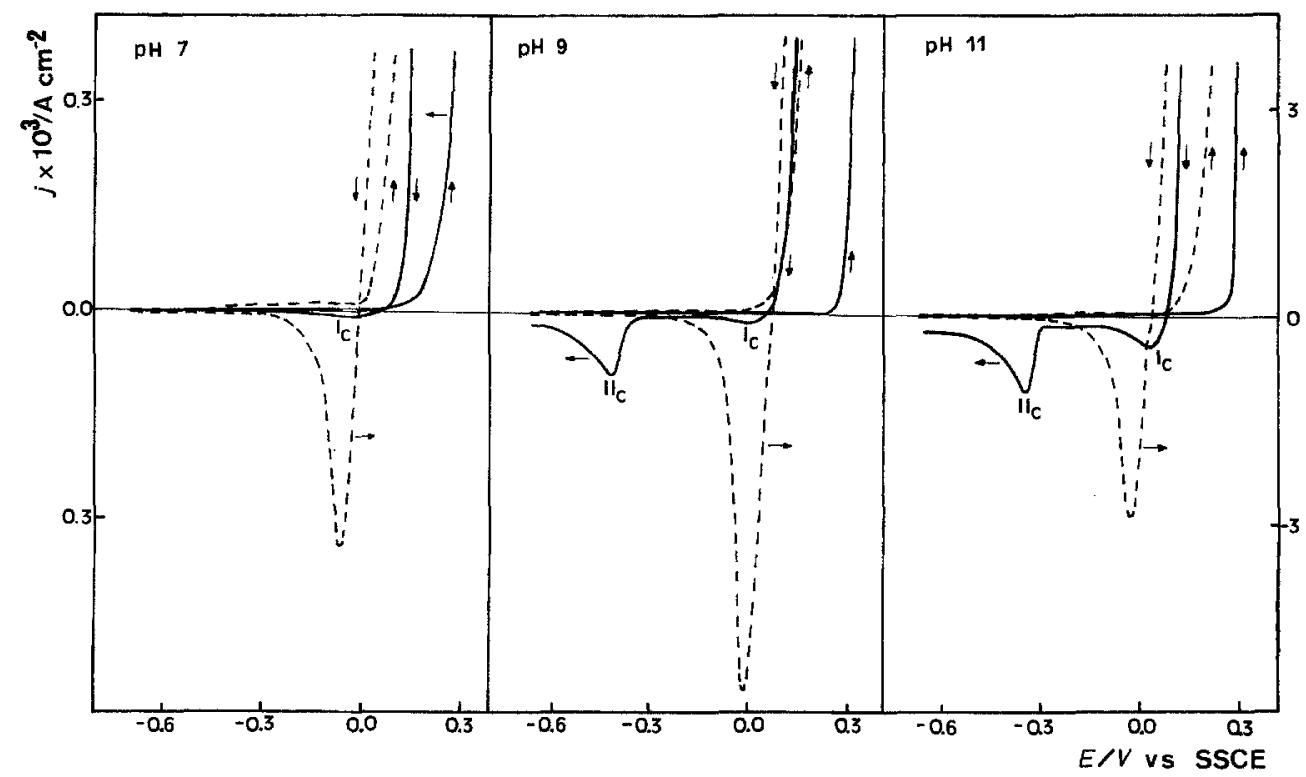

Fig. 1. Voltammograms of an annealed copper electrode at $0.01 \mathrm{Vs}^{-1}$ in $1 \mathrm{M} \mathrm{NaClO}_{4}+x \mathrm{mM} \mathrm{BTA}$ at $\mathrm{pH} 7,9$ and $11 ; 25^{\circ} \mathrm{C}$. Solid lines, $x=1$; dotted lines, $x=0$.

Measurements were made at $25.0 \pm 0.1^{\circ} \mathrm{C}$. Solutions were prepared from twice-distilled water and A.R. chemicals, and purged with argon prior to each run. The stock solution composition was $1 \mathrm{M} \mathrm{NaClO}_{4}+$ $x$ mM BTA $(0.5 \leqslant x \leqslant 2)$, its $\mathrm{pH}$ being adjusted to either 7,9 or 11 by adding diluted $\mathrm{NaOH}$ solution.

Each run was started by using a new copper specimen and by recording a cyclicvoltammogram at $0.01 \mathrm{~V} \mathrm{~s}^{-1}$ between -0.70 and $0.30 \mathrm{~V}$, to select the potential ranges most adequate for the application of the potentiostatic double step technique. The potential routine applied to the working electrode consisted of a potential hold for $3 \mathrm{~min}$ at $E_{\mathrm{c}}$, a potential close to the HER threshold potential. Subsequently, the potential was stepped for $100 \mathrm{~s}$ to $E_{\mathrm{k}}$, a potential within the potential range of $\mathrm{Cu}(\mathrm{I})$ oxide formation. Finally, the potential was stepped to $E_{\mathrm{s}}$, the latter being set in the copper electrodissolution potential range to record the anodic current transients. The potential sequence fits the condition $E_{\mathrm{c}}<E_{\mathrm{k}}<E_{\mathrm{s}}$.

SEM micrographs of the copper electrode surfaces were obtained with an Hitachi S-450 scanning electron microscope (SEM) for beam energies in the 20 to $25 \mathrm{kV}$ range.

\section{Results}

\subsection{Voltammetry and breakdown potentials}

In general, at the three $\mathrm{pH}$ values the voltammograms recorded at $0.01 \mathrm{~V} \mathrm{~s}^{-1}$ in $1 \mathrm{M} \mathrm{NaClO}_{4}$ (Fig. 1, dotted traces) and in $1 \mathrm{mM} \mathrm{BTA}+1 \mathrm{M} \mathrm{NaClO}_{4}$ (Fig. 1, full traces) exhibit two well defined potential ranges related to the passivity (region I) and to the corrosion of copper (region II). The positive going potential scan shows a very small current contribution in region I, and a rapid increase of the anodic current in region II when the positive going potential scan exceeds $E_{\mathrm{b}}$. Region II extends to lower potentials in the negative going potential scan displaying the typical hysteresis loop of pitting corrosion with a crossing point at the repassivation potential. In principle, the voltammetric behaviour for copper in these solutions is similar to that found for the breakdown of passive layers and initiation of pitting corrosion for a number of metals in aggressive environments [34-37].

The presence of BTA shifts the value of $E_{\mathrm{b}}$ positively, this effect being more remarkable at $\mathrm{pH} 9$. On the other hand, the comparison of the reverse potential scans show that the repassivation process tends to be independent of the presence of BTA at $\mathrm{pH}$ 9. Thus, at $\mathrm{pH} 7$, in the presence of BTA the value of $E_{\mathrm{b}}$ is $0.15 \mathrm{~V}$ and the hysteresis loop in the reverse scan extends to $0.08 \mathrm{~V}$. Likewise, when the potential scan enters region I, a small and broad cathodic current peak is recorded between 0.00 and $-0.10 \mathrm{~V}$ (peak $I_{c}$ ). At $\mathrm{pH} 9$, the value of $E_{\mathrm{b}}$ is close to $0.20 \mathrm{~V}$ and the reverse scan enters region $I$ at $0.04 \mathrm{~V}$. In this case peak $I_{c}$ becomes better defined, and another cathodic current peak appears at $-0.45 \mathrm{~V}$ (peak $\mathrm{II}_{\mathrm{c}}$ ). Finally, at $\mathrm{pH} 11$ the same features are observed, $E_{\mathrm{b}}=0.24 \mathrm{~V}$, the reverse scan enters region $I$ at $0.05 \mathrm{~V}$, and peaks $I_{c}$ and $\mathrm{II}_{c}$ are clearly observed, the potential of the former one being practically $\mathrm{pH}$ independent.

The cathodic peak $I_{c}$ can be assigned to the electroreduction of $\mathrm{Cu}$ (II) from the bulk solution and a possible adsorbed monolayer of a $\mathrm{Cu}(\mathrm{I}) \mathrm{BTA}^{-}$compound. Otherwise, peak $\mathrm{II}_{c}$, lying at potentials more negative than $-0.35 \mathrm{~V}$, can be related to the electroreduction of a strongly adsorbed $\left[\mathrm{BTA}^{-} \mathrm{Cu}(\mathrm{I})\right]_{x}$ layer formed during the preceding electroreduction process, yielding $\mathrm{Cu}+\mathrm{BTA}$ at the copper surface. This interpretation agrees with previous work on copper electrodeposition from solutions containing copper ionic species in the presence of BTA [38-40], and the polarographic investigations on the $\mathrm{Cu}(\mathrm{II})-\mathrm{Cu}(\mathrm{I})-$ $\mathrm{Cu}^{0}(\mathrm{Hg})$ system in the presence of BTA $[41,42]$.

The influence of the inhibitor in extending region I, i.e. to decrease the rate of formation of soluble copper species, and to promote the onset of passivity, is clearly seen from a comparison of voltammograms run in the 


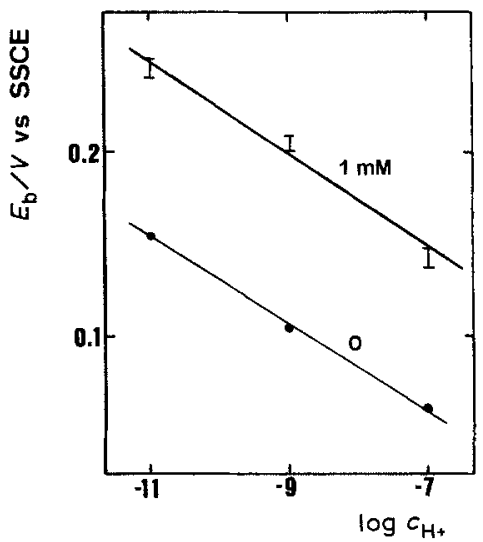

Fig. 2. Dependence of $E_{\mathrm{b}}$ values with $\log C_{\mathrm{H}}^{+}$both in the absence and in the presence of BTA.

presence and in the absence of BTA. In both cases the values of $E_{\mathrm{b}}$ shift positively as the $\mathrm{pH}$ of the solution increases fitting a linear $E_{\mathrm{b}}$ against $\log c_{\mathrm{H}^{+}}$relationship (Fig. 2) with the same slope which is close to $0.025 \mathrm{~V} / \mathrm{pH}$ unit (Fig. 2).

\subsection{Potentiostatic anodic current transients}

The potentiostatic current transients were run by using copper specimens previously held at $E_{\mathrm{c}}=$ $-0.70 \mathrm{~V}$ for $t_{\mathrm{c}}=3 \mathrm{~min}$ to attain the complete electroreduction of the copper surface, subsequently kept at $E_{\mathrm{k}}=0.00 \mathrm{~V}$ for $t_{\mathrm{k}}=100 \mathrm{~s}$ to form the anodic passive layer, and finally potential stepped to $E_{\mathrm{s}}$ to record the corresponding anodic current transient. The value of $E_{\mathrm{s}}$ was set in the 0.10 to $0.30 \mathrm{~V}$ potential range. Typical current transients are shown in Figs. 3-5 for $\mathrm{pH} 7,9$ and 11. In all cases the current increases steadily, the initial slope of the current transients increases with $E_{s}$, and for the highest values of $E_{\mathrm{s}}$ a current plateau is approached.

\subsection{SEM micrographs}

At the three $\mathrm{pH}$ 's SEM micrographs of copper specimens anodised at $E_{\mathrm{s}}>E_{\mathrm{b}}$ show pit-free domains and others with a large number of small crystallographic pits distributed at random (Fig. 6), and stepped polyhedrical surfaces, probably representing the proper bulk metal crystallographic lattice. Occasionally, pit

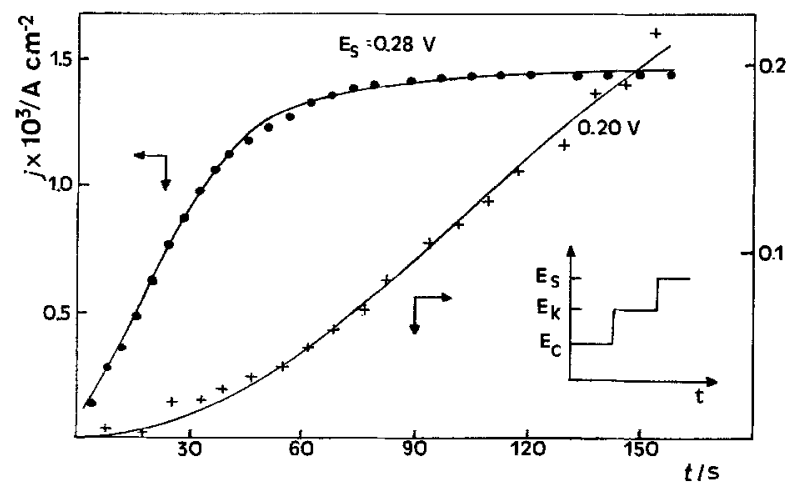

Fig. 3. Anodic current transients recorded at different $E_{\mathrm{s}}$ values in $1 \mathrm{M} \mathrm{NaClO}+4 \mathrm{mM}$ BTA at $\mathrm{pH}$ 7. The symbols denote the experimental data and the solid lines correspond to the current transients calculated with Equations 3 and 5 .

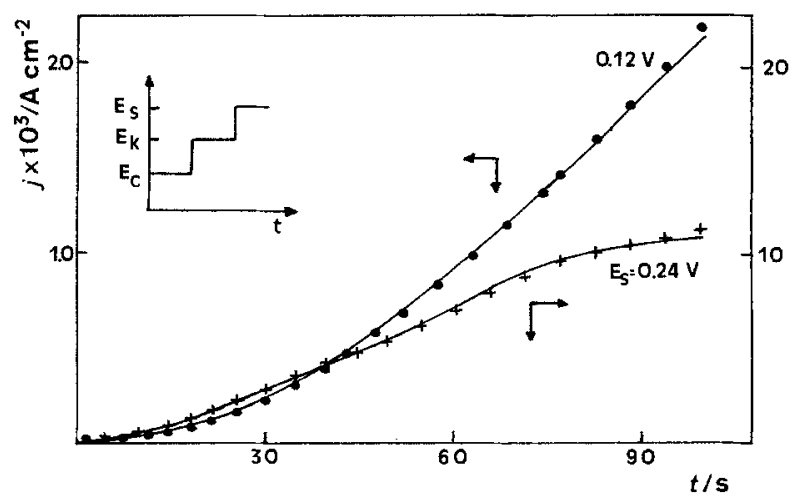

Fig. 4. Anodic current transients recorded at different $E_{\mathrm{s}}$ values in $1 \mathrm{M} \mathrm{NaClO} 4+1 \mathrm{mM}$ BTA at $\mathrm{pH} 9$. The symbols denote the experimental data and the solid lines correspond to the current transients calculated from Equations 3 and 5.

overlapping is also observed. The pit size is rather uniform with an average pit diameter of about $3.8 \mu \mathrm{m}$, suggesting that the initiation of pitting implies a probable instantaneous nucleation. The pit-free domains at the copper surface appear to be covered by a microcrystalline layer exhibiting the same topography as that already described for thick Cu-BTA films formed on copper [22].

\section{Discussion}

\subsection{General features of $B T A$ as $C u$ corrosion inhibitor}

The outer passive layer produced on copper immersed in aqueous solutions containing BTA at neutral and moderate alkaline $\mathrm{pH}$ values, in the absence of $\mathrm{Cl}^{-}$ ions, has been described as a polymeric, coherent and continuous film which is represented by the $\mathrm{Cu}(\mathrm{I})$ BTA basic stoichiometry $[13,14,17,20]$. This layer is formed by the irreversible chemisorption of BTA in solution on the copper surface. In agreement with results previously reported for copper corrosion inhibition by the presence of BTA in $1 \% \mathrm{NaCl}$ containing solutions [21], the present data confirm that the optimum efficiency of the inhibitor appears at pH 9. The loss of inhibiting efficiency at pH 11 may be due to the fact that in this case either the passivating layer is not completely coherent or that it changes the

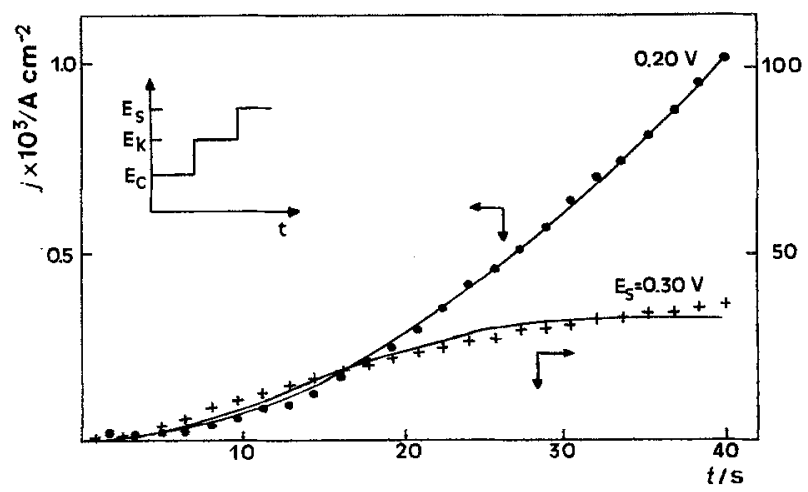

Fig. 5. Anodic current transients recorded at different $E_{\mathrm{s}}$ values in $1 \mathrm{M} \mathrm{NaClO}+1 \mathrm{mM}$ BTA at $\mathrm{pH} 11$. The symbols denote the experimental data and the solid lines correspond to the current transients calculated from Equations 3 and 5 . 

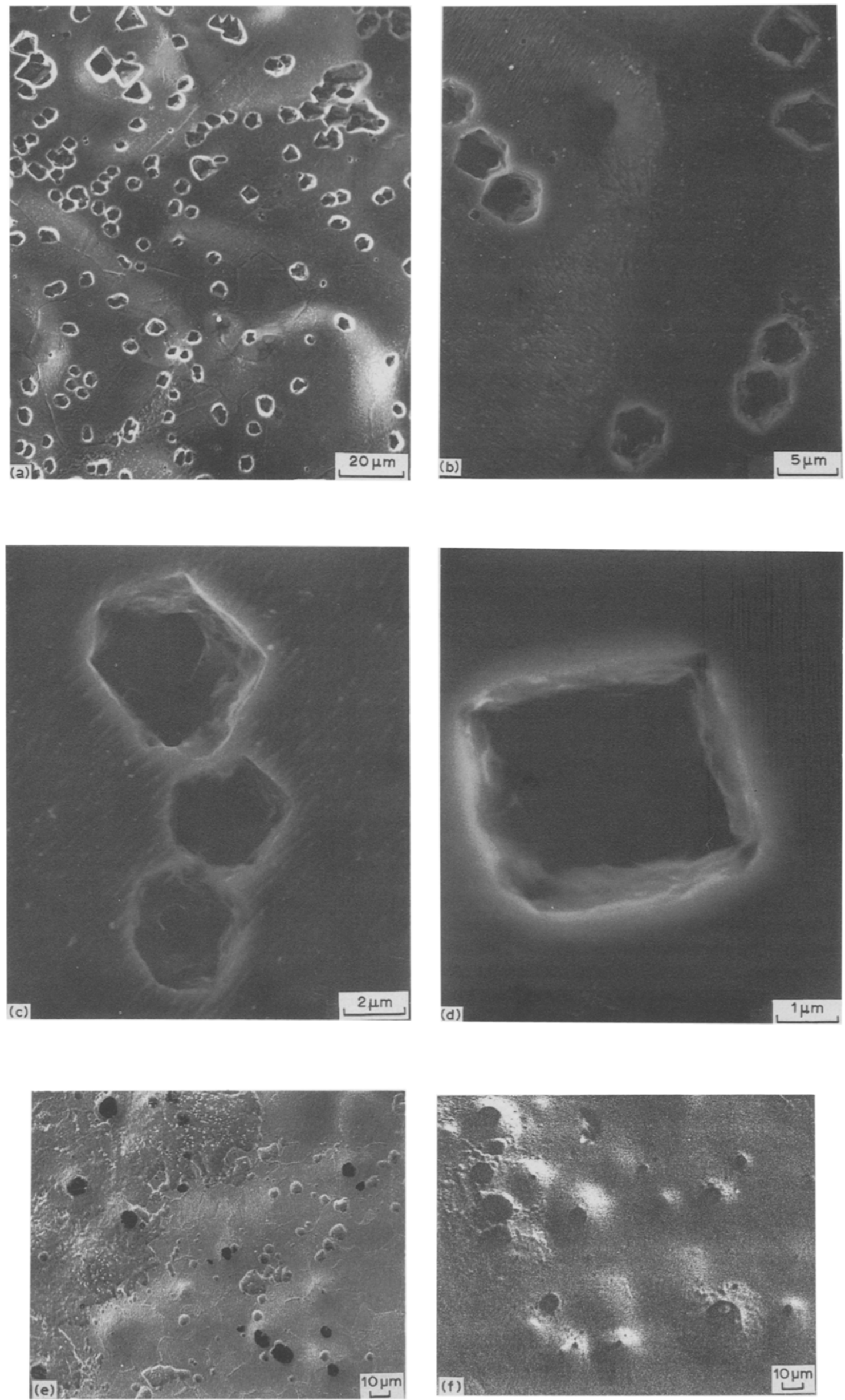

Fig. 6. SEM micrographs of an annealed copper specimen after anodising for $100 \mathrm{~s}$ in $1 \mathrm{M} \mathrm{NaClO}_{4}+1 \mathrm{mM} \mathrm{BTA}$. (a-d) $\mathrm{pH} 7, E_{\mathrm{s}}=0.23 \mathrm{~V}$; (e) $\mathrm{pH} 9, E_{\mathrm{s}}=0.24 \mathrm{~V}$; (f) $\mathrm{pH}=11, E_{\mathrm{s}}=0.25 \mathrm{~V}$. 
structure to become, to some extent, permeable to $\mathrm{OH}^{-}$ions and oxygen.

Otherwise, the comparison of the hysteresis loops obtained at different $\mathrm{pH}$ 's suggests that the reforming of the passivating layer becomes faster at low $\mathrm{pH}$. As the $\mathrm{pH}$ increases it appears that the competition between $\mathrm{OH}^{-}$-ions and BTA as film forming species moves in favour of the former. This is in agreement with previously reported data for BTA-benzylaminewater-methanol systems where the formation of thicker copper oxide underlayers takes place at the higher $\mathrm{pH}$ without improving the inhibiting efficiency of the passivating layer [21].

Despite the inhibiting properties of BTA for copper corrosion, the present results show that $\mathrm{ClO}_{4}^{-}$containing solutions can produce rupture of the passivating layer formed on copper in the presence of BTA, at all $\mathrm{pH}$ 's when the value of $E_{\mathrm{b}}$ is exceeded.

\subsection{Phenomenological description of anodic current transients}

The analysis of potentiostatic current transients allows exploration of possible mechanisms for copper pitting in BTA-containing solutions. For this purpose the nucleation and growth formalism can be used as a first approach to the problem.

Several current contributions can be considered in the current transients obtained at $E_{\mathrm{s}}$, namely, the current due to the double layer charging, the current related to the passive layer growth, the current for the base metal dissolution through the passive layer, and the copper pitting current. The sum of these contributions, $j_{\mathrm{t}}$, expressed as apparent current densities $j_{\mathrm{dl}}$, $j_{\mathrm{p}}, j_{\mathrm{d}}$ and $j_{\mathrm{c}}$, respectively, is

$$
j_{\mathrm{t}}=j_{\mathrm{dl}}+j_{\mathrm{p}}+j_{\mathrm{d}}+j_{\mathrm{c}}
$$

The double layer charging component quickly drops to zero so that in the time domain of the present study its contribution can be neglected. Moreover, as the copper specimens are anodised for $100 \mathrm{~s}$ in the passive potential range, the value of $j_{\mathrm{p}}$ can also be neglected. Thus Equation 1 reduces to

$$
j_{\mathrm{t}}=j_{\mathrm{d}}+j_{\mathrm{c}}
$$

On the other hand, as the contribution of the base metal electrodissolution is relatively small, this process can be modelled in the simplest way as the diffusion of copper cations from the metal surface through the passive layer to the bulk of the solution. Assuming a linear diffusion through a homogeneous thin passive layer, [43]:

$$
j_{\mathrm{d}}=P_{1} t^{-1 / 2}
$$

with

$$
P_{1}=z F D^{1 / 2} \Delta c \pi^{-1 / 2}
$$

where $D$ is the diffusion coefficient of copper cations through the passive layer and $\Delta c$ is the difference in the cation concentration at both sides of the passive layer. The term $j_{\mathrm{d}}$ can be specifically related to the growth of
Table 1. Parameters resulting from the anodic current transient fittings by using Equations 3 and 5

\begin{tabular}{rllll}
\hline$p H$ & $\begin{array}{l}\mathrm{E}_{s} \\
/ V\end{array}$ & $\begin{array}{l}\mathrm{P}_{1} \\
/ \mathrm{mAs} \mathrm{s}^{1 / 2} \mathrm{~cm}^{-2}\end{array}$ & $\begin{array}{l}\mathrm{P}_{2} \\
/ \mathrm{mA} \mathrm{cm} \mathrm{cm}^{-2}\end{array}$ & $\begin{array}{l}\mathrm{P}_{3} \\
/ \mathrm{s}^{-2}\end{array}$ \\
\hline 7.0 & 0.20 & $3.718 \times 10^{-3}$ & 0.284 & $4.72 \times 10^{-5}$ \\
7.0 & 0.23 & - & 0.081 & $5.19 \times 10^{-4}$ \\
7.0 & 0.28 & - & 1.401 & $1.28 \times 10^{-3}$ \\
9.0 & 0.12 & $1.55 \times 10^{-3}$ & 0.214 & $6.94 \times 10^{-5}$ \\
9.0 & 0.18 & - & $0.35 \mathrm{I}$ & $9.39 \times 10^{-5}$ \\
9.0 & 0.24 & - & 12.53 & $3.11 \times 10^{-4}$ \\
11.0 & 0.20 & 0.0 & 13.11 & $1.78 \times 10^{-4}$ \\
11.0 & 0.25 & - & 13.26 & $2.19 \times 10^{-4}$ \\
11.0 & 0.30 & - & 32.63 & $1.03 \times 10^{-3}$ \\
\hline
\end{tabular}

the outer portion of the anodic layer during corrosion. The rate of accumulation of the outer portion of the anodic layer should depend on $j_{\mathrm{d}}$, the solubility product of the $\mathrm{Cu}$-BTA species and copper oxide-hydroxides formed at the different $\mathrm{pH}$ 's, and on the diffusion rate of the soluble species towards the bulk of the solution. In the present case, due to the presence of BTA, resulting in very low currents for the electrodissolution process, the protective characteristics of the passive layer must be emphasized. Only when $E_{\mathrm{s}}$ lies close to $E_{\mathrm{b}}$, does the magnitude of the electrodissolution current approach that of $j_{c}$, being negligible for higher potentials. Therefore, under the present circumstances, since the contribution of the $j_{\mathrm{d}}$ term is not substantial, the influence of the electric field on the transport of copper ions through the passive layer can not be determined.

The apparent pitting current density, i.e., the $j_{c}$ term, can be ascribed to the instantaneous nucleation and three-dimensional growth of conical pits under charge transfer control, as given by the following equation [44]:

$$
j_{\mathrm{c}}=P_{2}\left[1.0-\exp \left(-P_{3} t^{2}\right)\right]
$$

where

$$
\begin{gathered}
P_{2}=z F k_{3 \mathrm{c}}^{\prime} \\
P_{3}=\pi M_{\mathrm{s}}^{2} k_{3 \mathrm{c}}^{2} N_{\mathrm{os}} \rho^{-2}
\end{gathered}
$$

and $k_{3 \mathrm{c}}$ and $k_{3 \mathrm{c}}^{\prime}$ are the growth rate constants parallel and perpendicular to the metal plane, respectively, $M_{\mathrm{s}}$ is the molecular weight of the salt whose density is $\rho$, and $N_{\text {os }}$ is the number of sites available for nucleation. This model appears to be useful when the applied potential is sufficently greater than $E_{\mathrm{b}}$. It should also be noted that for $P_{3} \Rightarrow 0$, then $\exp \left(-P_{3} t^{2}\right) \cong 1-$ $P_{3} t^{2}$ and Equation 5 leads to a simple relationship between $j_{\mathrm{c}}$ and $t^{2}$ :

$$
j_{\mathrm{c}} \cong P_{2} P_{3} t^{2}
$$

By using Equations 3 and 5 , the current transients shown in Figs. 3-5 can be reproduced with the set of parameters depicted in Table 1.

The comparison of the present results with those recently reported for BTA-free $\mathrm{ClO}_{4}^{-}$-containing solutions at different $\mathrm{pH}$ 's [37] show that the early stages of copper pitting in $\mathrm{ClO}_{4}^{-}$-containing solutions can be described by a common mechanism independently of 


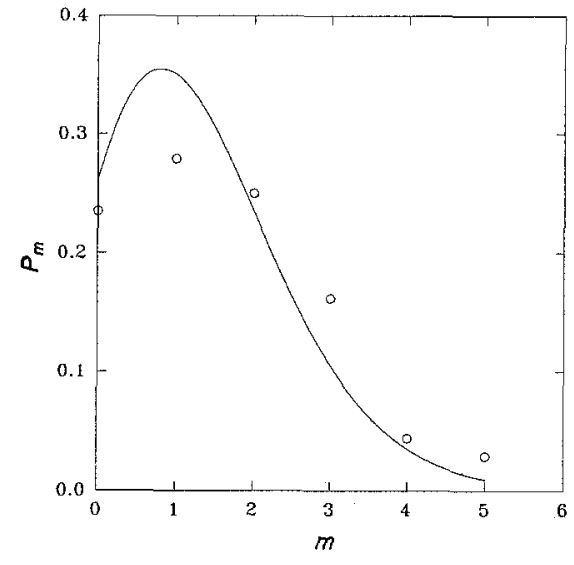

Fig. 7. $P_{\mathrm{m}}$ against $m$ plot for $E_{\mathrm{s}}=0.23 \mathrm{~V}, \mathrm{pH}$.

the presence of BTA as inhibitor. However, for the latter case, the nucleation and growth process leading to crystallographic pits is exclusively under activation control, although the value of $P_{3}$ is considerably lower than that reported for BTA-free $\mathrm{ClO}_{4}^{-}$-ion containing solutions. This fact permits Equation 5 to be used in the former case as a linearized $I$ against $t^{2}$ expression. The decrease of $P_{3}$ can be assigned to a decrease in $N_{0}$ due to the presence of BTA. As concluded from voltammetry and SEM data at $\mathrm{pH}>7$, the precipitation of $\mathrm{CuBTA}$ takes place at regions outside the pit domains.

\subsection{Spatial distribution of pits}

The spatial distribution of pits formed on the copper surface gives information about either the random or the non-random location of pits on the copper corroding surface [45].

Assuming that pits are randomly distributed on the copper surface and that the probability $\left(P_{\mathrm{m}}\right)$ of the number of pits $(m)$ occurring in arbitrary surface elements of the same size $(\Delta S)$. The value of $P_{\mathrm{m}}$ is then given by the Poisson equation [45]:

$$
P_{m}=N^{m} \exp (-N) / m !
$$

where $N$ is the average number of pits in the area $\Delta S$. In this case the value of $P_{m}$ can be calculated from the experimental results by dividing the number of surface elements containing $m$ pits by the total number of elements randomly located within the specimen surface. The circles in Fig. 7 denote the experimental probabilities, $P_{m}$, obtained for $\mathrm{pH} 7$ and $E_{\mathrm{s}}=0.23 \mathrm{~V}$, and the solid line illustrates the corresponding theoretical distribution resulting from Equation 9 with $\dot{N}=1.60$. These figures represent the experimentally found average number of pits corresponding to a surface element $\Delta S=3.8 \times 10^{-6} \mathrm{~cm}^{2}$.

In general, the reasonable agreement between theory and experiment suggests that the assumption of a random distribution of pits in the experimental system is correct. This implies that there is no marked influence of a pit on the nucleation and growth of other pits.

\section{Acknowledgement}

Financial support for this work by the Gobierno de
Canarias (Dirección General de Universidades e Investigación) under Contract No. 46/01.06.88, is gratefully acknowledged.

\section{References}

[1] U. Bertocci and D. Turner, in 'Encyclopedia of Electrochemistry of the Elements', (edited by A. J. Bard), Vol. 2, Marcel Dekker, New York (1974).

[2] J. van Muylder, in 'Comprehensive Treatise of Electrochemistry', (edited by J. O'M. Bockris, B. E. Conway, E. Yeager and R. E. White), Vol. 4, Plenum Press, New York (1981).

[3] H. D. Speckmann, M. M. Lohrengel, J. W. Schultze and H. H. Strehblow, Ber. Bunsenges. Phys. Chem. 89 (1985) 392.

[4] M. R. G. Chialvo, S. L. Marchiano and A. J. Arvia, J. Appl. Electrochem. 14 (1984) 165.

[5] M. R. G. Chialvo, Z. O. Zerbino, S. L. Marchiano and A. J. Arvia, ibid. 16 (1986) 517.

[6] J. Gómez Becerra, R. C. Salvarezza and A. J. Arvia, Electrochim. Acta 33 (1981) 613.

[7] M. Wanner, H. Wiese and K. G. Weil, Ber. Bunsenges. Phys. Chem. 92 (1988) 736

[8] M. R. G. Chialvo, R. C. Salvarezza, D. Vásquez Moll and A. J. Arvia, Electrochim. Acta 30 (1985) 1501.

[9] M. Pérez Sánchez, M. Barrera, S. González, R. M. Souto, R. C. Salvarezza and A. J. Arvia, ibid. 35 (1990) 1337.

[10] L. Horner and E. Pliefke, Wekstoffe und Korr. 33 (1982) 98

[11] J. B. Cotton, Proc. 2nd Int. Cong. Metallic Corrosion, NACE, New York (1963) p. 590.

[12] I. Dugdale and J. B. Cotton, Corros. Sci. 3 (1963) 69.

[13] J. B. Cotton and I. R. Scholes, Brit. Corros. J. 2 (1967) 1.

[14] G. W. Poling, Corros. Sci. 10 (1970) 359.

[15] F. Mansfeld, T. Smith and E. P. Parry, Corrosion 27 (1971) 289.

[16] F. Mansfeld and T. Smith, ibid. 29 (1973) 105.

[17] R. F. Roberts, J. Electron. Spectroscopy 4 (1974) 273.

[18] R. Walker, Corrosion 29 (1973) 290; 31 (1975) 97

[19] D. Chadwick and T. Hashemi, Corros. Sci. 18 (1978) 39

[20] T. Notoya and G. W. Poling, Corrosion 35 (1979) 193.

[21] M. Fleischmann, I. R. Hill, G. Mengoli and M. M. Musiani, Electrochim. Acta 28 (1983) 1325.

[22] T. Notoya and G. W. Poling, Corrosion 32 (1976) 216

[23] J. J. Kester, T. E. Furtak and A. J. Bevolo, J. Electrochem. Soc. 129 (1982) 1716.

[24] J. Rubim, I. G. R. Gutz, O. Sala and W. J. Orville-Thomas, J. Molec. Struct. 100 (1983) 571.

[25] M. Fleischmann, I. R. Hill, G. Mengoli, M. M. Musiani and J. Akhavan, Electrochim. Acta 30 (1985) 879.

[26] M. M. Musiani, G. Mengoli, M. Fleischmann and R. B. Lowry, J. Electroanal. Chem. 217 (1987) 187.

[27] R. Youda, H. Nishihara and K. Aramaki, Electrochim. Acto 35 (1990) 1011.

[28] W. Paatsch, Ber. Bunsenges. Phys. Chem. 81 (1977) 645.

[29] R. Alkire and A. Cangellari, J. Electrochern. Soc. 136 (1989) 913.

[30] D. Thierry and C. Leygraf, ibid. 132 (1985) 1009.

[31] S. L. F. A. Da Costa and S. M. L. Agostinho, J. Electroanal. Chem. 246 (1990) 57.

[32] M. M. Laz, R. M. Souto, S. González, R. C. Salvarezza and A. J. Arvia, Electrochim. Acta, 37 (1992) 655.

[33] D. Dickertmann, F. D. Koppitz and J. W. Schultze, Electrochim. Acta 21 (1976) 967

[34] D. V. Vásquez Moll, R. C. Salvarezza, H. A. Videla and A. J. Arvia, Corros. Sci. 24 (1984) 751.

[35] C. A. Acosta, R. C. Salvarezza, H. A. Videla and A. J. Arvia, ibid, 25 (1985) 291.

[36] R. C. Salvarezza, N. de Cristófaro, C. Pallotta and A. J. Arvia, Electrochim. Acta 32 (1987) 1049.

[37] R. M. Souto, M. Pérez Sánchez, M. Barrera, S. González, R. C. Salvarezza and A. J. Arvia, Electrochim. Acta, 37 (1992) 1437

[38] J. K. Prall and L. L. Shreir, Corros. Sci. 1 (1961) 181.

[39] B. S. Sheshadri, J. Electroanal. Chem. 61 (1975) 353

[40] J. C. Rubim, I. G. R. Gutz and O. Sala, ibid, 190 (1985) 55.

[41] F. Pergola, M. R. Moncelli and R. Guidelli, ibid, 107 (1980) 295.

[42] M. L. Foresti, F. Pergola and R. Guidelli, ibid, 107 (1980) 307.

[43] B. Scharifker and G. Hills, Electrochim. Acta 28 (1983) 879

[44] M. Y. Abyaneh and M. Fleischmann, Electrochim. Acta 27 (1982) 1513.

[45] R. C. Salvarezza, A. J. Arvia and A. Milchev, ibid. 35 (1990) 289. 